ISSN: 1641-4713; e-ISSN: 2081-1160

DOI: https://doi.org/10.36551/2081-1160.2021.27.95-112

\title{
Impressões da São Paulo nordestina: Entre territórios e identidades no imaginário coletivo
}

\author{
Impressions of São Paulo nordestina: Between territories and identities \\ in the collective imaginary
}

Elis Regina Barbosa Angelo

Universidade Federal Rural do Rio de Janeiro (UFFRJ), Brasil

ORCID iD: https://orcid.org/0000-0003-1799-3910

E-mail: elis@familiaangelo.com

Recepción: 11.01.2021

Aprobación: 1.06.2021

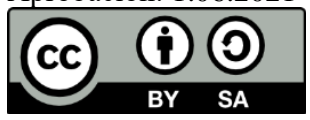

Resumo: O objetivo dessa análise está centrado na busca de elementos do imaginário social que definem as identidades culturais nordestinas formadas e mantidas fora do nordeste, em especial em São Paulo, um dos maiores centros de concentração de migrantes, no qual a religiosidade, a festividade e as imagens simbólicas desse imaginário formam espaços e palcos privilegiados para processos simbólico-territoriais de regionalização a partir de práticas culturais e devocionais que viajaram pelo Brasil e se alocaram na maior cidade do país. Dessa forma, foram privilegiadas para análise e interpretação, as formas de concepção desses lugares, suas definições e contornos na (trans)formação dos traços da cultura nordestina incluindo sotaques, cores, sabores, memórias e religiosidade nas maiores concentrações de nordestinos fora do seu lugar de produção de sentido. A partir dessas referências e representações culturais foram vislumbradas suas principais relações e sentidos na construção do imaginário para a sociedade. Como metodologia privilegiou-se a análise de imagens de lugares de memória e territórios que contemplam experiências e memórias migrantes, além de revisão bibliográfica sobre a produção das identidades. Como resultados se esmeram reflexões sobre a ideia de manutenção das identidades migrantes em outras terras por meio do imaginário coletivo.

Palavras-chave: migrações, identidades, imaginário, nordestinos, São Paulo. 


\begin{abstract}
The objective of this analysis is centered on the search for elements of the social imaginary that define the northeastern cultural identities formed and maintained outside the northeast, especially in São Paulo, one of the largest centers of concentration of migrants, in which religiosity, festivity and symbolic images of this imaginary form privileged spaces and stages for symbolic-territorial processes of regionalization based on cultural and devotional practices that traveled through Brazil and moved to the largest city in the country. Thus, the ways of conceiving these places, their definitions, and contours in the (trans) formation of the traits of the Northeastern culture, including accents, colors, flavors, memories, and religiosity in the largest concentrations of Northeasterners outside of their own, were privileged for analysis and interpretation place of production of meaning. From these references and cultural representations, its main relationships and meanings were glimpsed in the construction of the imaginary for society. As a methodology, the analysis of images of places of memory and territories that contemplate migrant experiences and memories was privileged, in addition to a bibliographic review on the production of identities. As a result, reflections on the idea ofmaintaining migrant identities in other lands through collective imagery are painstaking.
\end{abstract}

Keywords: migrations, identities, imaginary, Northeasterners, São Paulo.

\title{
INTRODUÇÃO ${ }^{1}$
}

As representações culturais do povo nordestino em outros territórios vêm ao longo do tempo causando diversas inquietações, especialmente sobre as referências da cultura popular e dos sentidos e significados produzidos sobre esses grupos que ora se diferencia por meio das peculiaridades por cidade/estado, ora se aglomeram por meio da imagem produzida sobre o "nordestino", significativamente debatido por não ser una e tão pouco engessada numa denominação criada e instigada por gerações. Dessa forma, a reflexão que se segue busca contemplar aspectos do imaginário sobre essa formação de sentidos das identidades, sejam forjadas pelos processos migratórios, de inclusão ou ainda necessários à multiplicidade de relações conduzidas a partir do outro, do lugar preconizado nas relações de poder ou mesmo de luta pelo espaço/território na cidade de São Paulo.

Busca-se, assim, refletir sobre a ideia de lugar, produzindo ou recriando a ambientação do "ser" e "estar" do Nordeste, a fim de destacar os laços de pertencimento criados nesse novo lugar, a cidade, que inclui também a arte popular, o artesanato, a música, a dança, os cheiros e até mesmo a moda. Neste contexto de multiplicação da história e memória do ser nordestino fora do seu espaço de criação do lugar, a cidade de São Paulo, exponencialmente uma das maiores em números de nordestinos fora do nordeste, foi palco dessa investigação, levando em consideração alguns dos territórios culturais numericamente mais visitados

\footnotetext{
${ }^{1}$ Os dados do trabalho aqui apresentado resultam de um projeto, realizado em estreita colaboração entre as duas autoras. Quanto à efetiva redação deste artigo, Elisabetta Santoro é responsável pelos parágrafos 1, 2, 4, 5, 6 e 7, e Giliola Maggio, pelo parágrafo 3.
} 
e experienciados pela identificação, pertencimento e concentração de migrantes, que, de certa forma também são significativos para a formação de espaços e territórios culturais como o bairro de Santo Amaro na atualidade, em especial o Lago Treze de Maio, pela concentração de lojas e comércio de produtos nordestinos, além da Biblioteca Belmonte, que retrata a literatura, os objetos e saberes do povo e fornece elementos de análise sobre a formação das representações e finalmente o centro de tradições nordestinas, que demonstra simbolicamente a cultura nordestina no imaginário da população.

Os moradores, turistas e visitantes da cidade de São Paulo ao perceberem as relações identitárias dos diversos grupos que dialogam e coexistem na megalópole, contemplam uma ligação com a história de seus antepassados, parentes e amigos, além da sua representação de lugar, fixada na diversidade de bairros, atrativos e territórios, seja pela definição deles em formato de grupos, seja pela relação desses com o outro. Assim, demonstram simpatia ou antipatia e identificação ou não com a diversidade de sabores, imagens, símbolos, sentidos e saberes em relação aos espaços e fronteiras que sintonizam nas peculiaridades e singularidades de cada um desses territórios.

Essa perspectiva de reconhecimento dos sentidos que os objetos e instrumentos de memória possuem para a história será fundamental para os objetivos desse projeto, pois ao considerar que os objetos de memória fazem parte da formação dos sujeitos na história busca-se entender como os sujeitos inscritos nesse novo espaço/território tratam as questões da memória, do passado, presente e futuro das representações identitárias.

Em São Paulo, por exemplo, o CTN - Centro de Tradições Nordestinas similarmente se alinha à formação de território cultural com a apropriação de temas, cores, sabores e sonoridades que corroboram para a identificação com o Nordeste. A relação do espaço criado com a finalidade de pertencer modela os sujeitos e suas práticas e cria representações da cultura popular (Rigamonte, 1997).

Esses territórios acabam por recriar ambientes e semelhanças que por meio do entretenimento forjam relações com os lugares de memória dos nordestinos da cidade grande, seja por meio da musicalidade, das sonoridades, da ambientação ou do show, as representações de alegria e de seleção de objetos de memória estão presentes.

Na perspectiva de Pierre Nora, os lugares se formam tanto da intenção em manter viva a imagem quanto da seleção de uma organização voluntária, intencional e seletiva. A memória só vive por meio dos objetos que a referencia (Nora, 1993). Os lugares de memória nascem de um sentido formado a partir do 
conceito de que não há memória espontânea considerando a necessidade que se tem em acumular vestígios, testemunhos, documentos antigos, entre muitos outros. São Paulo mantém um elo de pertencimento e identificação com as cidades que fazem parte do universo simbólico nordestino, ou seja, de onde vieram.

Essa escolha dos lugares e territórios de memória e suas contextualizações e experiências referem-se, de certa forma, ao universo de símbolos agregados ao ser, que passa pela discriminação, distinção e orgulho, dependendo da forma que é feita a leitura. $\mathrm{Na}$ atual conjuntura os objetos/pessoas/memórias e lugares passam a ter uma valorização diferente, passam a ser parte de um movimento de identificação e recriação de territórios culturais, pois a formação do patrimônio vislumbrado na relação de criação e aceitação passam a obter o que realmente faz sentido: o sujeito e sua identificação. Como mencionado por Bourdieu (1998), a simbologia depende de quem lhe atribui o valor.

Por meio dos estudos de Borges (2007), Albuquerque Jr. (1999), Penna (1992), conduziu-se a revisão bibliográfica sobre os nordestinos e suas referências, salientando a necessidade de pensar o imaginário sobre esses sujeitos que formam grande parte da população de São Paulo, seja como migrantes ou seus descendentes (Rigamonte, 1997). Também foram utilizados conceitos de imaginário de Durand (1988, 2004, 2007) e Mafessoli (2001) na apreensão dos sentidos de construção dessas identidades nordestinas.

\section{SÃO PAULO: NORDESTINOS, TERRITÓRIOS E REFERÊNCIAS DO IMAGINÁRIO}

Os migrantes eram colocados na boleia dos caminhões onde se sentavam em bancos de madeira. Para se apoiar, seguravam-se em tábuas (como se fossem barras) colocadas à frente de cada banco. Daí utilizar-se o termo "pau-de-arara" em analogia à maneira como essa ave se apoia para dormir. Durante o dia, sob sol ou sob chuva, à noite, cobertos por uma lona, os nordestinos viajavam durante muitos dias para chegar à cidade grande e "ganhar a vida". (Andrighetti, 2000, p. 111)

A chegada do nordestino na cidade de São Paulo não necessariamente foi articulada num lugar específico, como ocorre no caso de São Cristóvão, no Rio de Janeiro, onde houve uma maior concentração de nordestinos. As relações de atração e repulsão são formas de trazer novos sujeitos que compuseram os diversos espaços formando territórios de grupos e de sentidos tanto em São Paulo quanto no Rio de Janeiro.

O Nordeste do país tem um histórico de repulsão calçado pela pobreza, seca e outras motivações que o transformou num dos polos de maior rejeição do país, haja vista seus inúmeros quantitativos de saídas. Em contrapartida, os 
maiores polos de atração diziam respeito às maiores cidades nas décadas de 1930 a 1980, período em que as indústrias e o crescimento eram algo importante para a economia do Brasil. São Paulo tinha um slogan "a cidade que mais cresce no mundo", isso favorecia os deslocamentos oriundos da necessidade de mão de obra, tanto nacional quanto internacional, movimento que "atraía migrantes e imigrantes à cidade" (Galhardo, 2007, p. 3).

Dos lugares de concentração de grupos do Nordeste, representados numericamente estão o Largo da Concórdia, Parque da Luz, Parque Dom Pedro II, Largo da Batata, Largo do Japonês, Largo Treze de Maio, Mercado da Penha, Praça Central de São Miguel Paulista, Praça Silvio Romero e Praça da Árvore, entre outros (Borges, 2007).

Além das referências de produtos diversificados e da gastronomia nordestina, os lugares de sociabilidade e lazer como o Centro de Tradições Nordestinas e o Centro de Tradições Brasileiras que carregam aspectos ligados à cultura migrante nordestina, seja como identificador, seja como preconceito em relação aos grupos, acabam significando relações muito próximas com a cultura dos nordestinos (Borges, 2007).

No que se refere à identidade, as discussões sobre "ser nordestino" carregam tensões entre o que os identifica no grupo e o que os distancia da essencialização, muitas vezes transmutado de preconceitos e segregações. Para Woodward (2003) a identidade é relacional, reivindicatória, material e de autoafirmação. $\mathrm{Na}$ perspectiva de Borges, "não existe uma só cultura nordestina, mas várias, à medida que estas não são homogêneas e cada Estado tem as suas particularidades culturais" $(2007$, p. 21).

Para Borges (2007) há uma desconstrução e reconstrução e uma identidade, na qual se contrapõe os sentidos de si, os sentidos sobre si e os sentidos dados para si, levando em consideração as resistências, as redes de relações, os costumes, atitudes, comportamentos e suas respectivas origens e representações.

Sobre as representações Chartier (1990) as considera como discursos, carregados de sentidos que produzem estratégias e práticas indutivas. Nesse contexto, a ideia de leitura de um fenômeno não deve ser apreendida enquanto unitária, mas como uma leitura contraditória, repleta de tensões e de estratégias de sobrevivência e reinvenção, levando em consideração suas espacialidades e temporalidades.

No sentido de espacialidade, os grupos vão se formando a partir de referências e redes de ligação entre o lugar e as referências e tornando-se novos territórios compreendidos a partir disso. A esse exemplo, a organização espacial com êxito em Santo Amaro, especialmente pelo comércio de produtos nordesti- 
nos no Largo Treze de maio, formou-se a partir das proximidades do terminal rodoviário, onde conservou uma organização com características do Nordeste em São Paulo favorecendo a criação de lojas de produtos típicos nordestinos e caracterizando-o como reduto do grupo, mesmo que genericamente.

No que se refere a formação desses espaços, pode-se dizer que há uma relação dialética entre as categorias espaço e identidade, pois, no que se refere a formação dessas vivências nos lugares, corrobora-se com a ideia de que o espaço opera como meio de produção de identificação dos indivíduos com o seu mundo social, e, a partir daí se correlacionam as relações sociais, sentidos e significados que tangenciam a formação das identidades. (Berger \& Luckmann, 2004)

Atualmente, percebe-se um grande quantitativo de nordestinos e seus descendentes na cidade, localizados em sua diversidade espacial com territórios específicos como o Centro de Tradições Nordestinas, considerado um dos pontos de encontro do entretenimento e do lazer na cidade e o Largo Treze de maio, em Santo Amaro, um dos pontos de vendas de produtos nordestinos.

Pelas pesquisas desenvolvidas pelo IPEA, em 2011, 45\% da população paulistana se compõe de nordestinos e seus descendentes (IPEA, 2011). Em Santo Amaro, o comércio popularizado merece atenção, pois traz elementos que demandam um território do nordestino, seja nas cores, nos sabores e nos sentidos dados a esses objetos, formando o imaginário.

Para Durand (2007) o homem adota atitudes imaginativas a fim de significar algo reconfortante, e, essas atitudes por sinal, formam a percepção, produzindo símbolos, imagens, mitos e arquétipos, e, nessa confluência de elementos simbólicos forma o que se denomina de “imaginário". Durand (2007, p. 19) constrói uma base antropológica do imaginário, que pode ser percorrido tanto no sentido do biológico em direção ao social, como do social em direção ao biológico, formando o que se pode chamar de "ciência do imaginário".

No entorno do terminal Santo Amaro se concentram lojas em diversidade de produtos oriundos dos nove estados, tendo o Ceará como um dos mais procurados pelo gosto do consumidor local. Além dessas lojas estão os restaurantes na região, procurados pelo sentido que tem com os estados nordestinos. Junto a esse reconhecido território, encontram-se movimentos culturais populares que se atêm à cultura popular nordestina:

Em 2003, foi inaugurado o Núcleo de Cultura Popular e Repente de Viola na Biblioteca Belmonte. Este núcleo foi organizado pela comunidade formada por artistas da cultura popular nordestina, poetas cordelistas, repentistas, compositores, apreciadores da cultura popular, além da importantíssima participação da coordenadora da biblioteca que 
incentivou a criação do núcleo, cedendo espaço e organizando recursos humanos e estrutura para o projeto. (J. J. Santos, comunicação pessoal, 19 de maio, 2017) ${ }^{2}$

As atividades como biblioteca temática em cultura pop regional realizam diversas atividades que abraçam os âmbitos entre o popular, a tradição a devoção, a diversão, a comida, a feira e muitos outros atrativos que demandam não somente os signos do nordestino, mas as representações do povo. $\mathrm{O}$ acervo possui uma diversidade de objetos, cordéis, quadros, livros, periódicos, jornais, arte popular em cerâmica, artesanato popular, entre muitas representações populares dos nove estados que compõe o Nordeste brasileiro.

Esses elementos forjam sentidos alocados a outros grupos, por essa razão formam o que se pode chamar de imaginário nordestino. Durand define imaginário como o "conjunto das imagens e das relações de imagens que constitui o capital pensado do homo sapiens [...]” (Durand, 1997, p. 14).

\section{FiguRA 1. BiBLIOTECA BELMONTE}

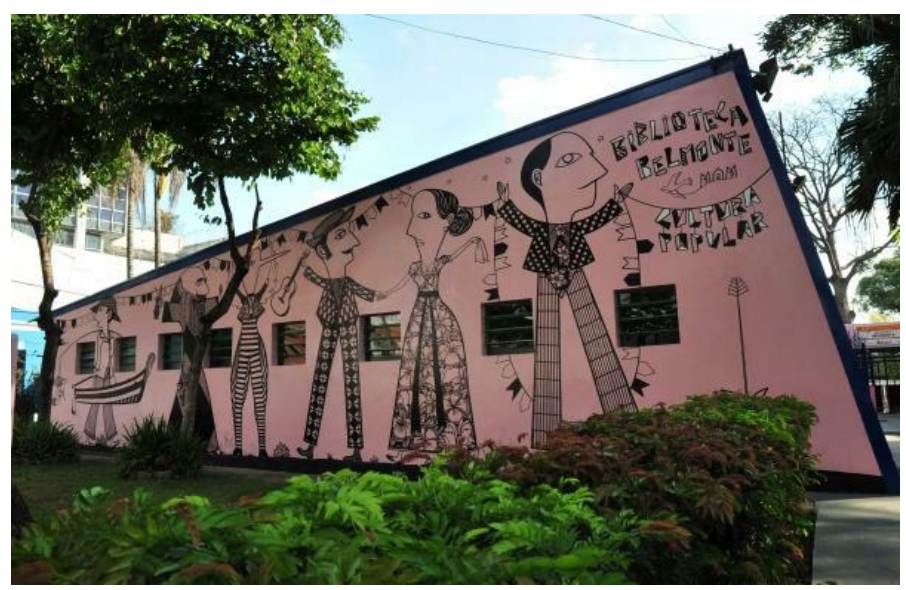

Fonte: Acervo da Biblioteca Belmonte, 2017.

O bairro já faz parte do imaginário dos nordestinos da cidade, reduto de comércio de Santo Amaro, compondo a história de mobilidade e de transforma-

\footnotetext{
2 Texto sobre o projeto da biblioteca e das atividades sobre cultura popular. "Participaram deste movimento os escritores Jorge Mello, César Obeid, Moreira de Acopiara, os repentistas Adão Fernandes e João Doto, Luzivam Matias e Sebastião Marinho, o Mestre em bonecos de Mamulengo Valdeck de Garanhuns, entre outros. Além de produzirem oficinas de xilogravura, cantoria pé de parede, oficinas de cordel, desafios de repente, emboladas, os integrantes do Núcleo iniciaram, por meio de doações a formação do acervo especializado em cordel e cultura popular. Realizaram também o Concurso de Literatura de Cordel, que contou com participantes de norte a sul do país" (J. J. Santos, comunicação pessoal, 19 de maio, 2017).
} 
ção dos espaços pelos migrantes. Dos territórios culturais compostos pelos nordestinos em São Paulo tanto o CTN quanto a biblioteca Belmonte se sobressaem pela quantidade de atrações, pelo público alcançado e pela diversidade de elos com a terra natal. A biblioteca conta com acervo e atividades diversificadas para o público em geral e foi criada:

(...) com a ideia de disseminar a cultura popular no bairro, este coletivo criou em 2003, o Núcleo de Cultura Popular da Biblioteca Belmonte. Participaram deste movimento os escritores Jorge Mello, César Obeid, Moreira de Acopiara, os repentistas Adão Fernandes e João Doto, Luzivam Matias e Sebastião Marinho, o Mestre em bonecos de Mamulengo Valdeck de Garanhuns, dentre outros. Além de produzirem oficinas de xilogravura, cantoria pé de parede, oficinas de cordel, desafios de repente, emboladas, os integrantes do Núcleo iniciaram, por meio de doações a formação do acervo especializado em cordel e cultura popular. Realizaram também o Concurso de Literatura de Cordel, que contou com participantes de norte a sul do país. Em 2005, por conta de um projeto do Sistema Municipal de Biblioteca de Criação de bibliotecas temáticas, e respeitando a vocação natural do bairro e o destaque da Biblioteca Belmonte, haja vista o sucesso do trabalho do Núcleo, a mesma foi escolhida para ser temática em cultura popular. Em 4 de agosto de 2007 foi inaugurada a Sala temática de Cultura popular, a Biblioteca Belmonte tornarase a partir daí, a segunda biblioteca temática da cidade. A primeira biblioteca temática em Cultura popular do país. (J. J. Santos, comunicação pessoal, 19 de maio, 2017) ${ }^{3}$

A biblioteca além de ser um acervo, conta com participantes do entorno, a fim de disseminar e manter a cultura popular como pano de fundo, promovendo oficinas, concursos, cursos, atividades de sociabilidade e interação com a comunidade de coparticipantes e de produtores de saberes da cultura nordestina, como repentistas, cordelistas, mestre de bonecos mamulengos, entre outros. Das ruas comerciais e pontos de encontro dos nordestinos estão:

No largo da Concórdia, na cidade de São Paulo, concentram-se muitas lojas de discos de músicas nordestinas, ponto de encontro de produtores de canções e literatura de cordel; armazéns de comidas e ingredientes vindos de todas as regiões do Nordeste como carne de sol, manteiga de garrafa, condimentos, pinga, pimenta, feijão de corda, rapadura, que se misturam às selas, às sandálias de couro, ao gibão, às ervas, aos remédios da terra, e outros signos nordestinos expostos à poluição da cidade. Nos últimos anos, muitas casas "nordestinas", tais como a Patativa, Danado de Bom, Remelexo e Centro de Tradições Nordestinas, este coligado à Rádio Atual, foram instaladas em São Paulo como lugares de lazer, entretenimento e culinária. (Galhardo, 2007, p. 16)

Tanto o Largo da Concórdia quanto o largo Treze de Maio encontram-se símbolos e comércio dos produtos oriundos do Nordeste, sendo transformados em "lugares" dos sabores, saberes e sentidos na cidade. Todavia, não elegeram um bairro para viver como outros grupos de migrantes e imigrantes, eles estão pela cidade toda, onde tiveram êxito pessoal no âmbito da grande metrópole.

\footnotetext{
${ }^{3}$ Proposta do projeto enviada pelo senhor Jomar. Dados referem-se à concepção e aos espaços criados na biblioteca.
} 
Numerosos foram os contingentes migratórios para a metrópole e para cidades do Estado entre os anos de 1930 a 1980, com continuidades posteriores e com retornos atualmente percebidos nos deslocamentos pelo país.

Figura 2. Monumento ao Migrante Nordestino - CONCÓRDiA/SP

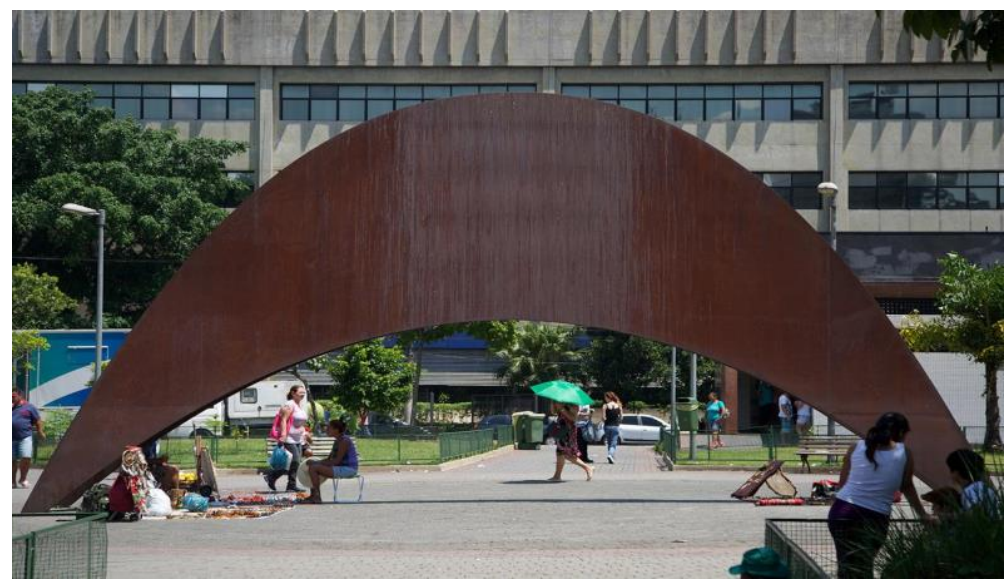

Fonte: Zito, 2010.

O monumento erigido no Largo da Concórdia foi uma iniciativa do Memorial do Imigrante em homenagem aos migrantes nordestinos, pois, o bairro possui um significativo quantitativo de moradores migrantes e descendentes e, de certa forma, faz parte do imaginário sobre os nordestinos, pela relação de grupos e identidades pertencentes ao bairro.

Sobre a conexão dos bairros com os grupos e sua diversidade, pode-se dizer que, o Brás é considerado um bairro acolhedor para os migrantes, pois, tanto de chegadas quanto moradia, tornou-se uma referência de migrantes nordestinos:

Nas décadas de 30 e 40 passou por grande apogeu comercial. Seu esvaziamento e a chamada "deterioração" datam da década de 50, por efeito da metrópole industrial, das alterações dos seus sistemas viários, e pelos fluxos migratórios nacionais, que marcaram o começo da nordestinação. Com a implantação do metrô, nos meados da década de 70 , o bairro se descaracteriza, recrudesce o encortiçamento e seu feitio cultural é nordestino, com suas feiras, seus ambulantes. (Véras, 1994, p. 600)

Maffesoli (2001) refere-se ao imaginário como uma fonte racional e não racional de impulsos para a ação, além de represar sentidos, emoções, vestígios, imagens, sentimentos de afetos, símbolos e valores que vão culminar na escolha e definição dos sentidos sobre a produção material e imaterial das identidades. Essa referência forma também o conceito de território urbano, como mencionam Rolnik et al. (2008), o espaço social vivido. 
A cidade de São Paulo ganha contornos do grupo migrante em vários bairros onde a quantidade de conterrâneos crescia vertiginosamente pelos laços de solidariedade e sociabilidade, além da periferização dos grupos marginalizados pela condição socioeconômica das suas origens e motivações de vinda.

Antes dos anos 50, São Paulo já apresentava profundos contrastes socioeconômicos. A imagem da cidade, desde os anos 1930, estava atrelada a da modernidade, em prol da exaltação do progresso. Era uma urbe que vinha se remodelando com o passar das décadas, mediante a verticalização, a substituição no transporte coletivo do bonde pelo ônibus, o crescimento do número de veículos, proveniente da implantação da indústria automobilística em território nacional. (Paes, 2009, p. 99)

Os contastes vão formando os espaços urbanos, dando faces e definindo identificações, pode-se dizer que o espaço social vivido, nesse caso, vai desenhando identidades e pertencimentos que porventura serão referências de migrantes nordestinos posteriormente.

\section{LAZER E IDENTIDADES EM PERSPECTIVA E O RESSIGNIFICAR DOS BAIRROS}

\section{São Paulo Gigante}

Oh! Meu São Paulo gigante,

Metrópole da nações.

Tu tens o poder triunfante,

De prender os corações.

Vinte cinco de janeiro, Data que ficou na história Por um povo hospitaleiro,

É festejada com glória.

A tão famosa garoa A penumbrar a cidade Vai molhando a terra boa Com gotinhas de saudade.

Oh! metrópole querida

Amada por todos nós A tua fama é conhecida

E como cresces veloz.

Vinte e cinco de janeiro Data que ficou na história Por um povo hospitaleiro, É festejada com glória.

Analice Feitoza de Lima 
A São Paulo nordestina ganha força numérica de indivíduos e coletivos oriundos dos nove estados nordestinos. Essa referência se mistura com os grupos migrantes que em diversos momentos históricos fizeram da cidade, - uma das mais acolhedoras do país. Apesar dos inúmeros formatos e trejeitos que vão formando as diversas identidades, os lugares se formam e ganham delineamentos que condizem e representam a diversidade desse acolhimento.

Apesar do ponto de migração ter como referencial os anos 30, e ser essa época em que a migração foi oficialmente motivada pela atração (a partir de São Paulo) e repulsão (a partir do Nordeste), os migrantes já entravam na cidade há algum tempo em busca de novas oportunidades. Por motivações de escassez de trabalho e renda, no caso dos nove estados de repulsão, quanto da cidade que emergia com o funcionamento da industrialização e havia diminuído a imigração dos braços de lavoura, os números de entrada cresciam e iam ressignificando os bairros, lugares e formando territórios culturais dos grupos. "A indústria e as estações de trem e de ônibus foram fatores determinantes no processo de formação dos bairros periféricos, como o Brás, o Belenzinho e a Mooca, e de toda a rede de bairros que emergiram ao redor das linhas ferroviárias, que percorriam toda a zona leste da cidade." (Paes, 2009, p. 101)

Na cidade, por um lado, tinha-se a construção do discurso da paulistaneidade e, em condição paralela, o discurso de Nordeste. Monumentos como o Pátio do Colégio marcaram a fundação da cidade enquanto ícones da "invenção da paulistaneidade". Em contrapartida, as casas de forró, as feiras típicas nordestinas e os centros de tradição ocuparam espaços simbólicos dentro da cidade como ícones da "invenção de nordestinidade", materializando a presença nordestina na urbe e representando outros marcos e ícones de resistência e negociação entre as diversas correntes sócio-políticas. (Paes, 2009, p. 108)

Apesar dos discursos que ora se formavam, especialmente de contradição, os diversos territórios representativos culturais ganham força e definição na escolha da diversão, da sociabilidade e mesmo da união de esforços na luta pelo espaço e pelo reconhecimento dessas diversas identidades. O Centro de Tradições Nordestinas (CTN) não é diferente dessa perspectiva.

A história do Centro faz parte da concepção de um empresário paulistano, José de Abreu, que fundou em 1990 a primeira rádio, a Rádio Atual (AM 1370 $\mathrm{KHZ}$ ), a trazer música nordestina para a cidade. A ideia era trazer músicas regionais e "ser a voz dos nordestinos na capital e na grande São Paulo" (Abreu, 2016).

Em maio de 1991, foi inaugurado o Centro de Tradições Nordestinas, tendo como princípio a mesma direção da rádio. Ou seja, "reconhecer a cultura nordestina e homenagear esse povo tão sofrido e discriminado que ajudou a cons- 
truir São Paulo, hoje a sétima maior cidade do mundo em população.”, segundo Abreu (2006, p. 18).

Sobre a formação do CTN como local de expressão popular referente aos nordestinos, o trabalho feito por Rigamento (1997) traz aspectos da representação do nordestino, buscando refletir como esses indivíduos constroem e reafirmam sua identidade por meio das redes de sociabilidade. Nessa análise, e, a partir das entrevistas, menciona práticas de lazer, tradição e sociabilidade nas manifestações do CTN, precisamente como esse ressignificar de práticas produz sentidos na afirmação da identidade, apesar das transformações oriundas desse processo de interação com outras culturas numa cidade múltipla como São Paulo. "O CTN, espaço que existe há mais de duas décadas busca recriar um clima interiorano, com barracas cujas mesas e cadeiras estão dispostas ao ar livre e onde são servidas comidas típicas do Nordeste.” (Borges, 2007, p. 52)

Apesar dos espaços serem formados a partir das necessidades de lazer e entretenimento dos diversos grupos que constroem a diversidade nordestina na São Paulo miscigenada, ainda se percebe uma forma de referência muitas vezes negativada e pejorativa impondo-lhe relações sociais e definindo grupos, isso é percebido nos discursos, na mídia, nas formas de tratamento, na exclusão, e em tantas outras formas de ligação dos sujeitos pertencentes aos migrantes.

FiguRA 3. FACHADA DO CENTRO DE TRADIÇÕES NORDESTINAS

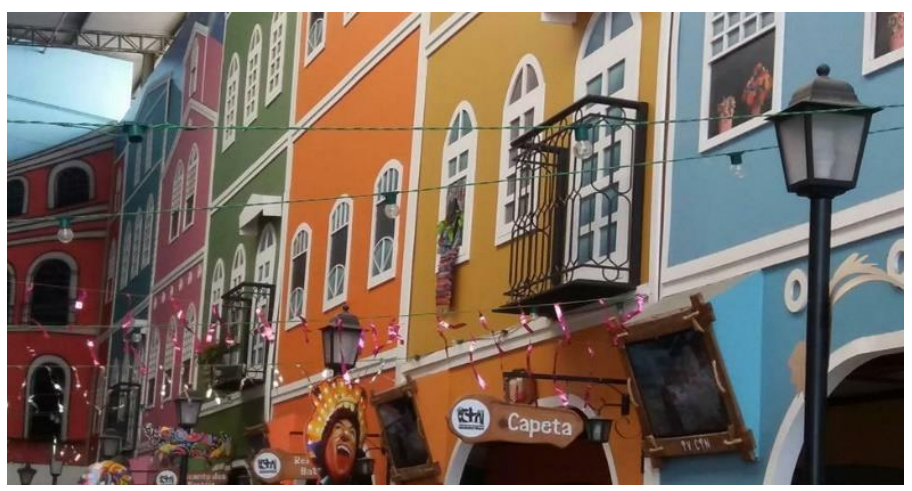

Fonte: Foto da autora, 2017.

Das propostas deste reconhecimento dos nordestinos na cidade, compôsse em princípio como lazer, a fim de trazer um pouco da cultura popular, da música, da dança, da comida e da religiosidade simbolizada na imagem de padre Cícero Romão Batista e de Frei Damião como ícones do povo nordestino. 
A imagem do padre Cícero faz parte da relação de fé e simbolismo religioso popular dos visitantes do centro. Os símbolos e as ideias referentes ao Nordeste vão compondo os espaços de produção de sentidos que o território reconstrói para atender às expectativas do público.

O território, nesse caso, compõe-se de memórias, de reinvenções da produção de uma percepção imagética, contextualizada num passado imaginário e de experiências familiares, passadas ou recriadas pelos sujeitos que visitam e almejam ter um acolhimento de lembranças passadas e de lugares que contém essa possibilidade.

Figura 4. PADRE CíCERO NO CENTRO DE TRADIÇÕES NORDESTINAS

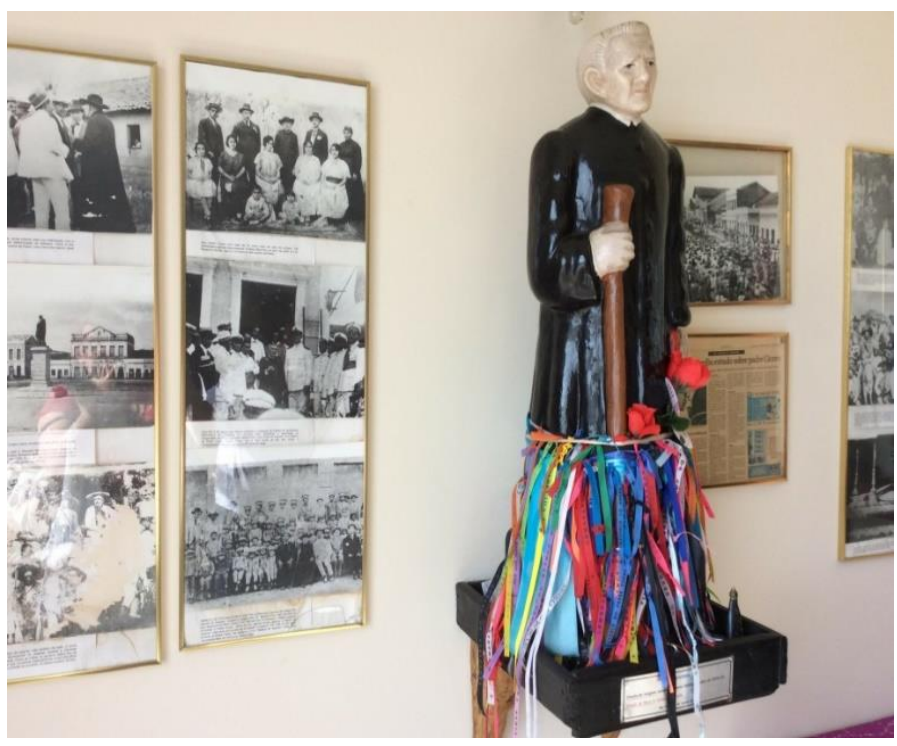

Fonte: Foto da autora, 2017.

Tanto as imagens religiosas como o padre Cícero quanto os objetos de memória do passado, como seu carro, documentos e ornamentos pessoais, vão compondo o que se chama de "lugar de memória." (Nora, 1993).

O padre Cícero e o Frei Damião formam laços com os conterrâneos, visitantes, curiosos e com pessoas que tem na fé os santos emocionalmente constituídos, haja vista ainda estar em processo a canonização de Cícero Romão Batista. Como os nordestinos já o evocaram enquanto santo, indiferente da religião católica e da aprovação da Igreja, o sentido e os sentimentos vão se atrelando à imagem recriada neste território. Das atividades mais significativas para o âmbito 
social, encontram-se celebrações de casamentos coletivos; o projeto "Vila Social", que desde 2013 oferece atividades de reforço escolar e recreação para mais de 60 crianças entre 4 e 12 anos das comunidades do entorno do CTN, zona norte de São Paulo.

Cursos profissionalizantes, CTN cidadão (uma iniciativa que oferece bimestralmente profissionais para prevenção de doenças como diabetes, pressão arterial, avaliação oftalmológica e odontológica), além de serviços que buscam promover o bem-estar de moradores das comunidades, como corte de cabelo e estética. Também em período bimestral, ocorrem ações como orientação jurídica e emissão de documentos para cidadãos do entorno. Outras atividades realizadas pelo centro estão doações de alimentos, doação de leite, promoção de cursos profissionalizantes e demais atividades de recreação e lazer.

A identidade e o imaginário nordestinos também se consagram nas comemorações, comemoram no dia 08 de outubro, o dia do nordestino, com o intuito de celebrar as raízes e tradições culturais. Além disso, também é comemorado neste mesmo dia o centenário do poeta popular cearense Patativa do Assaré. Demais atividades recreativas seguem o calendário de eventos da cidade de São Paulo, identificando aspectos importantes de suas identidades, pois, “(...) uma pessoa pode usar a diversidade de modo a criar uma auto-identidade distinta que incorpora positivamente elementos de diferentes cenários numa narrativa integrada" (Giddens, 1997, p. 175).

Para melhor conectar essa relação, também se faz necessário compreender que indivíduos transitam entre diversos mundos, especialmente ao assumir papéis, distintos por meio de adaptação e transformação oriunda de múltiplos códigos que foram traduzidos e adaptados em universos distintos, e, desse modo, forjam e constroem identidades multifacetadas, ou metamorfoses (Velho, 1994).

Sobre esse processo definido por Velho (1994), a movimentação entre os diversos códigos (geralmente formas de interação, identificação e interação) também se alinha ao que define como potencial metamorfose.

Essa movimentação dos códigos, distribuída desigualmente por toda a sociedade vai ganhando aspectos de cada código que melhor se assemelha aos seus interesses, apesar de que as experiências mais distintas mantêm de certa forma, "uma identidade vinculada a grupos de referência e implementada através de mecanismos sociais básicos" (Velho, 1994, p. 29).

Gilberto Velho reflete sobre a unidade que o indivíduo representa e sua capacidade de permanecer idêntica a si mesma numa sociedade que a obriga, e valoriza, mudanças permanentes no processo de interação, e, a essa relação de 
metamorfose, vai se definindo aspectos dinâmicos. A metamorfose seria o processo social pelo qual, através da movência contínua entre códigos, o indivíduo se reconstrói de maneira permanente.

Percebe-se que ao mesmo tempo, os indivíduos acabam compondo a sua identidade a partir dessa multiplicidade mudanças e permanências atreladas ao "uno", ainda que multifacetado, atuando de acordo com o contexto.

\section{CONSIDERAÇÕES PROVISÓRIAS}

Os migrantes e a migração fazem parte do olhar sobre as cidades, das mesmas sua essência e em sua transformação ao longo dos anos. Do início, até o período abordado sobre a formação do Centro de Tradições Nordestinas, muitas são as interpretações e os estudos sobre os contextos de formação do território.

Esse território, formado a partir das relações sociais vividas, entremeia os sentidos e significados do que é "ser nordestino" na cidade de São Paulo, especialmente define e referencia os grupos e sua diversidade que a cada momento emerge em luta por discursos mais positivos de si e sobre si seja pelos monumentos seja pelo respeito às diversas formas de e/i/migração que formou tanto modelos quanto formatos de bairros e seus desenhos.

Essa relação se estabelece em meio a preconceitos e estereótipos formados pela elitização de lugares, especulação imobiliária, favelização e outros meios de separação pessoas pela classe, gênero e lugar. A relação passa por questões de poder, de identificação, de repulsa e mesmo de preconceito, mas define grosso modo, um indivíduo migrante capaz de adaptar-se e demonstrar ao mesmo tempo, uma forma de sobressair na múltipla São Paulo.

O conceito de cidade de Sodré (2002), amalgamando aos sujeitos e tudo que produzem como sensibilidades e formas de criar identificações, orientam sobre a definição e conceituação dos territórios como reorganizações da vida cotidiana com sentidos e sentimentos do passado.

Os territórios produzidos pelos grupos possuem elos e representações que coexiste em vários espaços, e, esses, por sinal, muito têm a dizer sobre os seus visitantes, sobre os usuários e, especialmente, sobre os nordestinos que vivenciam, frequentam e apreciam o que é representado em suas vidas cotidianas, seja pela perspectiva identitária, seja pela memória imaginária sobre seus antepassados.

As mudanças e as permanências se configuram a partir dos sentidos dados nesse novo lugar, no qual se concentra as relações dinamizadas pela formação deste território, local onde se mantém de certa forma, uma relação mais estreita 
com a terra natal, com o Nordeste dos antepassados, configurando uma imagem criada pela mídia, pelas narrativas do passado ou, ainda, pelos anseios relacionados ao passado.

A referência de "ser nordestino" em cidades metropolitanas como São Paulo, vai delineando novos sujeitos que divergem e convergem em momentos distintos para a conformação das identidades, muitas vezes forjadas pela necessidade de afirmação do passado e negadas pelas relações do presente.

Apesar de serem distintas as relações de criação e pertencimento, os territórios mantêm similaridades que definem a apreciação ao "lugar" criado para si enquanto sujeito social carregados de estigmas e referências culturais. Esses territórios vão configurando novas relações com as cidades.

O nordestino se (re)configura nesses territórios. Muitos são os contrastes, mas as vozes tentam definir o passado como ponto de partida de si, de seus anseios e de suas angústias. O que parece certo é a direção de manter viva a memória dos sujeitos que trouxeram para a cidade e para o bairro esse ar de "diferente", de "singular" e de "plural".

Os sujeitos e os lugares transformados em memórias carregam as identificações da terra natal, do imaginário das pessoas e dos que vieram em busca de uma nova vida. Os estereótipos existem, mas cabe a cada um redesenhar os conceitos de si e do lugar para que este seja efetivado como metamorfose. Um lugar de saudade, de identificação e de relação, onde cada indivíduo colabora para a formação e desmistificação da memória de forma coletiva. Os territórios se formam e ressignificam os grupos ao passo em que firmam a luta pela igualdade e reconhecimento dos sujeitos que também formam a urbe.

Tanto o imaginário como as identidades vão formando desenhos sobre os grupos, sobre sujeitos e mesmo sobre sua forma de metamorfose como Velho (1987) define. As identidades múltiplas são expressas em formas de ser e de sentir dos sujeitos oriundos de tantos brasis que foram os estados do Nordeste, que, grosso modo, se encontram em significados e símbolos como formas de interação e de união, mas que são dinamicamente múltiplos na sua essência. A partir de discursos menos engessantes os grupos vão sendo delineados, em meio a metamorfose que os define e os distancia, em especial pelas adaptações e transformações que indivíduos e grupos ressignificam ao longo das gerações. 


\section{REFERÊNCIAS BIBLIOGRÁFICAS}

Abreu, C. (2016). Um pedaço do Nordeste em São Paulo (2a ed.). CTN.

Andrighetti, Y. (2000). Nordeste, Mito e Realidade. Moderna.

Berger, P., \& Luckmann, T. (2004). A construção social da realidade: Tratado de sociologia do conhecimento (24a ed.). Vozes.

Borges, S. S. (2007). O nordestino em São Paulo: desconstrução e reconstrução de uma identidade [Dissertação de mestrado, Pontifícia Universidade Católica de São Paulo]. Biblioteca Digital PUC-SP. https://sapientia.pucsp.br/bitstream/handle/13035/1/Selma\%20Santos\%20Borges.pdf

Chartier, R. (1990). A História Cultural entre práticas e representações. Bertrand Brasil.

de Albuquerque Jr., D. M. (1999). A Invenção do Nordeste. Cortez.

Durand, G. (1988). A imaginação simbólica. Cultrix; EDUSP.

Durand, G. (1997). As estruturas antropológicas do imaginário. Martins Fontes.

Durand, G. (2004). O imaginário. Rio de Janeiro: Difel.

Durand, G. (2007). As estruturas antropológicas do imaginário. Presença.

Galhardo, S. (2007). Os conterrâneos nordestinos na metrópole de São Paulo: Seus símbolos, sua memória e seus mitos. Anais do III ENECULT - Encontro de Estudos Multidisciplinares em Cultura. Faculdade de Comunicação/UFBa, 23-25.05.2007, Salvador, Brasil. http://www.cult.ufba.br/enecult2007/SoledadGalhardo.pdf

Giddens, A. (1997). A constituição da sociedade. Martins Fontes.

IPEA (Instituto de Pesquisa Econômica Aplicada). (2011). Perfil dos migrantes em São Paulo. Comunicado do IPEA. Secretaria de Assuntos Estratégicos da Presidência da República.

Maffesoli, M. (2001). A Transfiguração do Político: A tribalização do mundo. Sulina.

Nora, P. (1993). Entre história e memória. A problemática dos lugares. Projeto História, (10), 7-28.

Paes, J. M. (2009). São Paulo em noite de festa: Experiências culturais dos migrantes nordestinos (1940-1990) [Dissertação de Mestrado, Pontifícia Universidade Católica de São Paulo]. Biblioteca Digital PUC-SP. https://tede2.pucsp.br/bitstream/handle/13134/1/Jurema\%20Mascarenhas\%20Paes.pdf

Penna, M. (1992). O que faz ser Nordestino: Identidades sociais, interesses e o "escândalo" Erundina. Cortez.

Rigamonte, R. C. (1997). Sertanejos Contemporâneos: Entre a metrópole e o Sertão [Dissertação de mestrado, Universidade de São Paulo].

Rolnik, R., Nakano, K., \& Cymbalista, R. (2008). Urban Land and Social Housing in Brazil: the issue of land. In: Participatory Master Plans. The Challenges of Democratic Management in Brazil: the right to the city. São Paulo: Instituto Pólis/Fundação Ford.

Sodré, M. (2002). Antropológica do espelho: Uma teoria da comunicação linear e em rede. Vozes.

Velho, G. (1987). Individualismo e Cultura: Notas para uma Antropologia da sociedade contemporânea. Jorge Zahar. 
Velho, G. (1994). Projeto e metamorfose: Antropologia das sociedades complexas. Jorge Zahar.

Véras, M. P. B. (1994). Cortiços no Brás: Velhas e novas formas de habitação popular na São Paulo industrial. Análise Social, 29(127), 599-629.

Woodward, K. (2003). Identidade e diferença: Uma introdução teórica e conceitual. In T. T. da Silva (ed.), Identidade e diferença: a perspectiva dos estudos culturais (pp. 7-71). Vozes.

Zito, R. (2010). SP 460 anos. Monumentos para entender. Esculturas e marcos da capital paulista ajudam a explicar trajetória da metrópole. G1. http://g1.globo.com/sao-paulo/sp-460/spem-monumento/platb/category/sem-categoria/ 